\title{
Is the Anatomy of External Anal Sphincter Fully Understood?
}

ISSN: 2578-0379

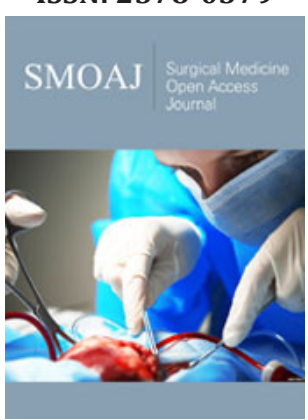

*Corresponding author: Gargi Soni, Department of Anatomy, Malaysia

Submission: 粡 August 12, 2019

Published: 些 August 22,2019

Volume 3 - Issue 1

How to cite this article: Gargi Soni. Is the Anatomy of External Anal Sphincter Fully Understood? Surg Med Open Acc J.3(1). SMOAJ.000551.2019. DOI: $10.31031 /$ SMOAJ.2019.03.000550.

Copyright@ Gargi Soni, This article is distributed under the terms of the Creative Commons Attribution 4.0 International License, which permits unrestricted use and redistribution provided that the original author and source are credited.

\author{
Gargi Soni* \\ Department of Anatomy, Malaysia
}

\section{Introduction}

The external anal sphincter is an elliptical cylinder of striated muscle that envelops the entire length of the inner tube of smooth muscle, but it ends slightly more distal than the internal anal sphincter. Knowledge of the exact anatomy of the anal sphincter complex is essential for management of pathology in this area. Many anatomical and radiological studies of the external anal sphincter have been conducted till date and yet there is no consistent and consensual description of EAS. Various researchers have described the anatomy of external anal sphincter; some authors suggested it to be a single continuous sheet; others described it to be a bilaminar structure and still further it was suggested to be a triple loop system. However, most of the modern-day anatomy and surgery textbooks describe the three parts of the external anal sphincter as subcutaneous, superficial and deep. Milligan \& Morgan [1] reported that the external anal sphincter consists of subcutaneous, superficial and profundus components. Goligher et al. [2] on the other hand, found no suggestion of division of the external anal sphincter into separate parts: the muscle was considered to be a single continuous sheet.

Oh \& Kark [3] proposed a 2 compartment organization, a 'superficial compartment' (subcutaneous and superficial parts of EAS were included here) and the 'deep compartment' (comprising of the deep part of EAS and puborectalis), on the basis of the close anatomical relationship between each of these two pairs of muscles. Shafiq [4] suggested that external sphincter is composed of three separate U-shaped loops of fibers. The base loop (subcutaneous part) encircles the anus and some fibers are attached to the perianal skin. The intermediate loop (superficial part) surrounds the anal canal, attached posteriorly to the coccyx through the anococcygeal ligament and anteriorly to the perineal body. The top loop (deep part) surrounds the ano-rectal junction and loops forward as pubo-rectal sling to gain attachment to the lower part of the pubic bone. Shafiq considered the puborectalis as a part of the top loop of external anal sphincter and not belonging to levator ani.

These concepts were based on dissection studies, histological studies in three dimensional planes and often strengthened by surgical experience [5]. The differences in the results of these authors might have originated from using different dissection techniques and the problematic dissection of the sphincteric complex. The advent of imaging technologies such as anal endosonographic and earlier magnetic resonance (MR) studies did not help resolve the confusion over EAS subdivisions. The divisions of the EAS are not visible on anal endosonographic [6]. The earlier MR imaging studies used endoanal coils to improve visibility of sphincter structures. This had the disadvantage of distorting the sphincter complex. Both DeSouza et al. [7] and Williams et al. [6] found 3 subdivisions of the EAS similar to Lawson's [8] observations. However, Hussain et al. [9] proposed that the EAS was indeed a two-part structure; the deep EAS was most likely the puborectalis muscle. These disagreements may have arisen from limited image quality of earlier MRI [10].

With improved MR imaging, authors have consistently observed a separation in the EAS. Peschers et al. [11] used both MRI and cross-sectional anatomy to evaluate the sphincter. They could see a clear separation between the subcutaneous and deep external anal sphincter; However, no further separations could be seen on either anatomic or MR images to further 
subdivide the deep portion. Morren et al. [12] found 2 components of the EAS with MRI, which they referred to as the deep and a superficial component.

Hsu et al. [13] used the magnetic resonance images of living women and 3-dimesional modeling software and identified 3 components of the EAS that met criteria as being "separate" structures. The main body (EAS-M) was separated from the subcutaneous external anal sphincter (SQ-EAS) by a clear division that could be observed in all of the MRI scans reviewed. The third part was the wing-shaped end (EAS-W, its fibers did not cross the midline ventrally, but had lateral origins near the ischiopubic ramus. Mittal et al. [14] used three-dimensional transperineally ultrasound imaging, MRI, diffusion tensor imaging, and muscle fiber tracking, and delineated various components of the EAS and their muscle fiber directions. These novel imaging techniques suggested that EAS is not circular but had "purse-string" morphology, with "EAS muscles" crossing contralaterally in the perineal body to the contralateral transverse perineal (TP) and bulbospongiosus (BS) muscles, thus attaching the EAS to the pubic rami. Mittal et al. [14] also suggested that EAS had two parts and the deep part was the puborectalis muscle. Most of the authors could easily differentiate the subcutaneous and the deep parts of the external anal sphincter but the major controversy revolves around the subdivisions of the deep part. Even today, despite of the fact that many studies using different approaches have been conducted, the relationship among the three muscles (external anal sphincter, puborectalis and levator ani) still remains unclear. Therefore, further studies are necessary to define the detailed anatomy of the external anal sphincter.

\section{References}

1. Milligan ETC, Morgan CN (1934) Surgical anatomy of the anal canal. Lancet 224(5804): 1150-1156.

2. Goligher JC, Leacock AG, Brossy JJ (1955) The surgical anatomy of the anal canal. British Journal of Surgery 43(177): 51-61.
3. Oh C, Kark AE (1972) Anatomy of the external anal sphincter. British Journal of Surgery 59(9): 717-723.

4. Shafik A (1975) A new concept of the anatomy of the anal sphincter mechanism and the physiology of defecation. The external anal sphincter: A triple-loop system. Investigative Urology 12(5): 412-419.

5. Dalley AF II (1987) The riddle of the sphincters. The morpho physiology of the anorectal mechanism reviewed. American Surgeon 53(5): 298306.

6. Williams AB, Bartram CI, Halligan S, Marshall MM, Nicholls RJ, et al. (2002) Endosonographic anatomy of the normal anal canal compared with endocoil magnetic resonance imaging. Dis Colon Rectum 45(2): 176-183.

7. DeSouza NM, Puni R, Kmiot WA, Bartram CI, Hall AS (1995) MRI of the anal sphincter. J Comput Assist Tomogr 19(5): 745-751.

8. Lawson JO (1974) Pelvic anatomy. II. Anal canal and associated sphincters. Ann R Coll Surg Engl 54(6): 288-300.

9. Hussain SM, Stoker J, Lamiris JS (1995) Anal sphincter complex: Endoanal MR imaging of normal anatomy. Radiology 197(3): 671-677.

10. Hussain SM, Stoker J, Zwamborn AW, Den Hollander JC, Kuiper JW, et al. (1996) Endoanal MRI of the anal sphincter complex: Correlation with cross-sectional anatomy and histology. J Anat 189 (Pt 3): 677-682.

11. Peschers UM, DeLancey JO, Fritsch H, Quint LE, Prince MR (1997) Crosssectional imaging anatomy of the anal sphincters. Obstet Gynecol 90(5): 839-844.

12. Morren GL, Beets TRG, van Engelshoven JM (2001) Anatomy of the anal canal and perianal structures as defined by phasedarray magnetic resonance imaging. Br J Surg 88(11): 1506-1512.

13. Hsu Y, Fenner DE, Weadock WJ, DeLancey JO (2005) Magnetic resonance imaging and 3-dimensional analysis of external anal sphincter anatomy. Obstet Gyneco 106(6): 1259-1265.

14. Mittal RK, Bhargava V, Sheean G, Ledgerwood M, Sinha S (2014) Pursestring morphology of external anal sphincter revealed by novel imaging techniques. American Journal of Physiology-Gastrointestinal and Liver Physiology 306(6): G505-G514. 